\title{
Developing a Remote Practice for Laboratory Experiments on Measuring Instruments
}

\author{
http://dx.doi.org/10.3991/ijoe.v10i5.3833 \\ Yassine Khazri ${ }^{1}$, Mohammed Rouane ${ }^{1}$ Ahmed Fahli ${ }^{1}$, \\ Mohammed Moussetad ${ }^{1}$, Abdelatif Khaldouni ${ }^{2}$, Ahmed Naddami ${ }^{1}$ \\ ${ }^{1}$ Hassan II University Mohammedia-Casablanca, Department of Physics, Casablanca,Morocco \\ ${ }^{2}$ Hassan I University Settat, Department of Physics, Settat, Morocco
}

\begin{abstract}
E-learning environments are becoming increasingly popular in higher education. One of the most important e-learning resources is the remote laboratory. It gives students opportunities to learn technical training through internet, perform real experience and interact with real equipment and real instruments laboratory.
\end{abstract}

This paper describes the development of interactive remote laboratory that allows learners to use, control and interact with the measuring instruments used in the real laboratories (like oscilloscope, GBF...). Therefore, we chose to put the manipulation of the signal treatment module on line.

Index Terms-Remote laboratory, Experience, Engineering education, Software, Tele-TP.

\section{INTRODUCTION}

As we know, the learning process depends on the way learners get information and experience learning. Practical work in laboratories provides students with the experience they need to help them understand theories taught in classroom. But the increasing number of students in universities and the high cost of equipment reduce practical work in laboratory[1].

In order to overcome this problem and improve and level of learning, we suggest an interactive platform that links the real world to experimentation through Internet technology[2].

This modern technology offers a new way of producing, distributing and receiving engineering education. It also completes traditional teaching and learning methods for learners. Remote labs are flexible and decentralized environments which enable learners to perform real experiments with the real instruments via the web and also allow them to try and correct errors with real data analysis. However, the virtual laboratories don't use the real instrument or real data, because they are based on simulations $[1,3]$.

The developments of the remote laboratories have other motivations and advantages like:

- Improving the e-learning platforms that require practical activities.

- Eliminating time and space constraints (Accessi at anytime and anywhere);

- Experiments are real and run at the real time;

- Sharing expensive and heavy materials among universities
- Reducing the cost of equipment and instruments used in the laboratory;

- Reducing the cost of maintenance of laboratory equipment;

- Protecting the students and environment in dangerous tests (kind of nuclear testing);

- Protecting the materials from the vicious use or human errors.

The purpose of this study is to build an interactive remote laboratory for learners which allows them to use, control and interact with the measuring instruments used in the real laboratories based on control interface. It also provides learners with access to measuring instruments of remote laboratory by delivering different activities related to digital signal processing and measurement experiments.

\section{LABORATORY ARCHITECTURE}

The development of a remote laboratory includes the analysis of user requirements, remote control functionalities, simultaneous user operation, sharing the online data from an experiment, read data, change variables and controlling equipments. Functional requirements are associated with specific functions or services that the system must support.

The architecture for practical work is presented in Figure 1. With this architecture, the learners will be able to send themselves, orders through the web browser. These orders will be sent by the user to the practical work server, and then will execute the experience in the real device. The practical work server retrieves results and sends them to the user's interface. The existence of a webcam laboratory helps the learners to have a clear concept about different aspects of the real experiment as if it took place in a conventional laboratory, also to drive the experience and visualize it in real-time.

In the case of a remote laboratory with several practical works available, we use a program of management of resources and users in order to optimize the use of the platform of remote laboratory.

\section{DESCRIPTION OF THE EXPERIENCE}

We chose the manipulation of spectral analysis of the periodical signals, in order to demonstrate that a nonsinusoidal signal can be decomposed into a Fourier series. Putting themselves in the particular case of periodic signals, we will conduct its analysis by frequency, that is, we will reveal the first harmonic component. 


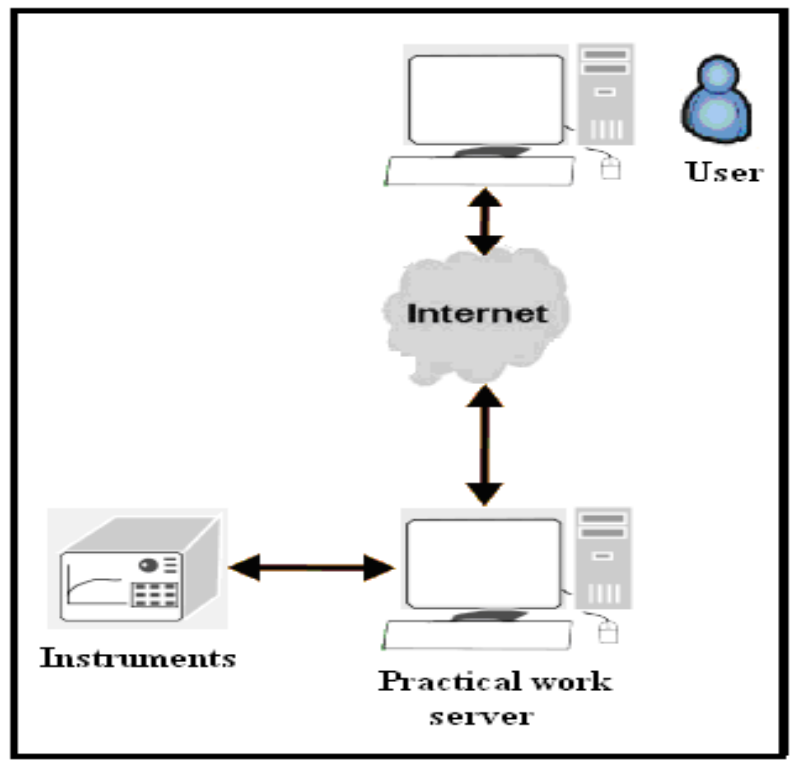

Figure 1. Remote Practical work.

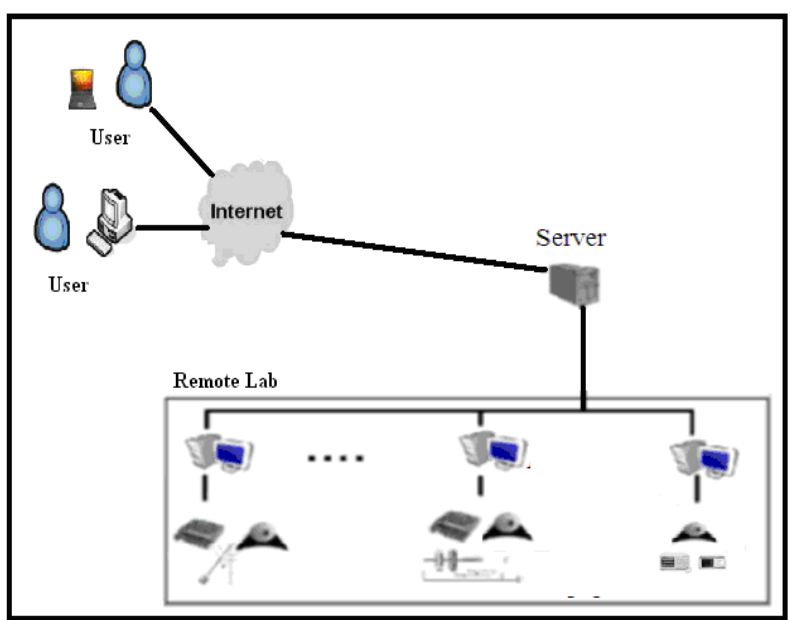

Figure 2. Architecture of Remote Laboratory.

These harmonics are characterized by their amplitude and frequency and are to be compared with the theoretical values.

We know that any periodic signal of period $\mathrm{T}$ can be decomposed into a limited or unlimited sum of sinusoids whose frequencies are integer multiples of the fundamental frequency: $f_{1}=\frac{1}{T}$

$v(t)=v_{0}+v_{1} \sin \left(\omega_{1} t\right)+v_{2} \sin \left(2 \omega_{1} t\right)+v_{3} \sin \left(3 \omega_{1} t\right)+$

$v_{4} \sin \left(4 \omega_{1} t\right)+\ldots .+v_{k} \sin \left(K \omega_{1} t\right)$

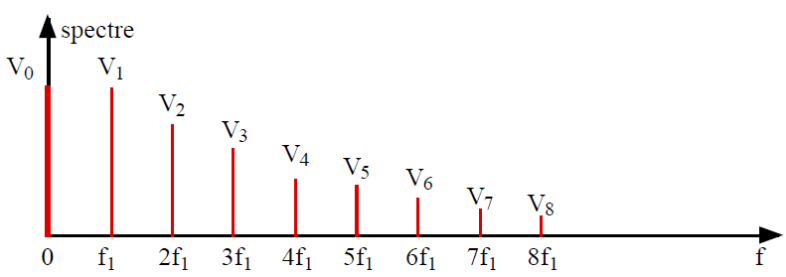

Figure 3. The frequency spectrum of $v(t)$.
In mathematics, any periodic function can be represented by either a sine function or a cosine function and can be written in a general manner:

$v(t)=A_{0}+\sum_{1}^{\infty} A_{n} \cos \left(n \omega_{1} t\right)+\sum_{1}^{\infty} B_{n} \sin \left(n \omega_{1} t\right)$

The sinusoid of frequency f1 is called the fundamental frequency. And the sinusoids n.fl are called harmonics $\mathrm{n}$.

\section{SOFTWARE STRUCTURE}

Software structure of this remote experimental consists of two main parts (Figure.4): Client side and Server lab side.

\section{A. Client side}

The user access to remote experimental by web browser, A Java Applet that runs on web browser connects to server laboratory. This applet has the interface of virtual GBF and oscilloscope. It can change the frequencies, signal type, amplitude of GBF, or change, control and select the operation mode of oscilloscope as well as direct visualization of the experience through the webcam.

\section{B. Server lab side}

The server lab side consists of three components: Web Server, Java Server Application and control Application which is developed by LabVIEW and C language.

\section{1) Web Server}

When the user accesses to Web Server, request web page the Java Applet resides in.

\section{2) Java Server Application}

Once Java Applet is started in user computer, it sets up a socket connection with Server Application which is also developed by Java [4]. This application is responsible for directing data and control flow between Client and Control Program.

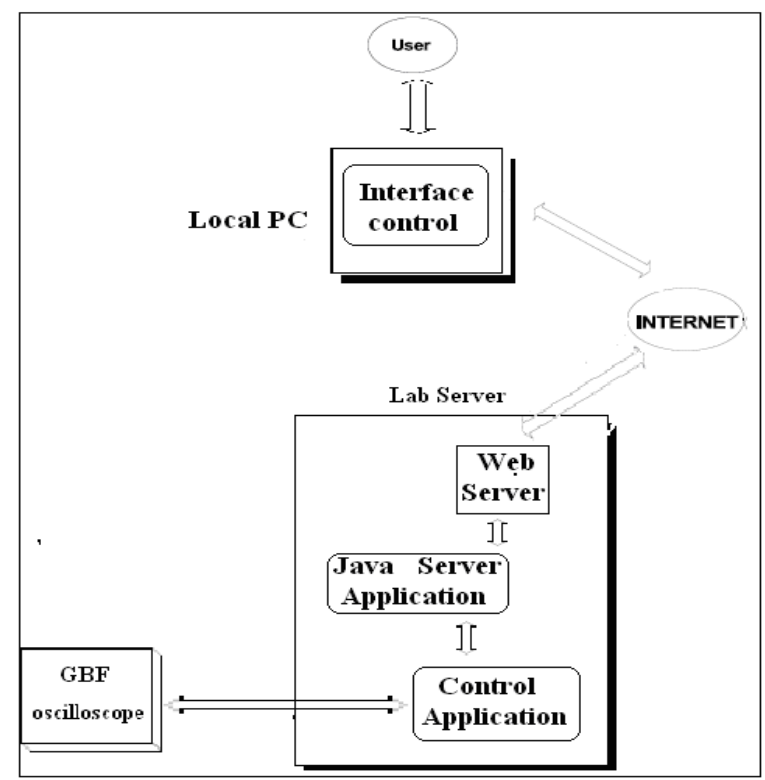

Figure 4. Schematic representation of the software realization. 


\section{3) Control Application}

Main role of the Control Application is to pass the orders received from the user and to collect the results data from the GBF and oscilloscope. This software is developed using LabVIEW VI that converts these commands into DLL (Dynamic Link Libraries). DLL files provide flexibility to the developers as they are easy to upgrade and there is no need for recompilation. These DLL files are then invoked inside C language code for compilation[5].

\section{HARDWARE STRUCTURE}

Hardware of this remote practice has three main parts. These are a Server Machine, the used instruments and a Web cam.

\section{A. Server Lab}

This computer is a host for software components of system, and the essential software running on this Computer is LabVIEW, and is also connected with the used instruments via USB.

\section{B. The used instruments}

For this experiment will be used:

- The low frequency generator GBF that generates AC signals (sinusoidal and triangular square).

- The numerical oscilloscope to display the periodic spectral signal.

\section{Web cam}

Web camera is used to see the real experiment instruments while working.

\section{CONCLUSION}

The remote practical work on measuring instruments provides a mechanism to control the process remotely through the Internet.

Therefore the used LabVIEW with the necessary toolboxes has played an important role in developing fast and practical solutions, as well as in creating the remote control interface for the instruments, allowing thus students to work on real operations and interact with real equipment and real laboratory instruments without having to be present in the laboratory.

\section{ACKNOWLEDGMENT}

This project has been funded with support from the European Commission. This publication reflects the views only of the author, and the Commission cannot be held responsible for any use which may be made of the information contained therein.

\section{REFERENCES}

[1] A.NADDAMI, A.FAHLI, K.CHOUKRI and M.MOUSSETAD "Creating online leading University laboratories" International Conference on Engineering Education and Research 1 July - 5 July 2013, Marrakesh.

[2] A. Rojko, D. Hercog, K. Jezernik "E-training in mechatronics using innovative remote laboratory" Mathematics and Computers in Simulation 82 (2011).

[3] C.Barros, C.P.Leão, F.Soares, G.Minas, J.Machado "RePhyS: A Multidisciplinary Experience in Remote Physiological Systems Laboratory" iJOE Volume 9, Special Issue 5: "EDUCON2013", June 2013.

[4] E. Fabregas, G. Farias, S. Dormido-Canto, S. Dormido, F. Esquembre "Developing a remote laboratory for engineering education" Computers \& Education 57 (2011).

[5] C.M.Markan, Satendra Gupta, Sajal Mittal and Goutam Kumar "Remote Laboratories - A Cloud Based Model for Teleoperation of Real Laboratories" iJOE - Volume 9, Issue 2, May 2013.

\section{AUTHORS}

Yassine Khazri is with Hassan II University Mohammedia-Casablanca, Department of Physics, Avenue Hassan II B.P. 150 Mohammedia Morocco, (khazri10@gmail.com.)

Mohammed Rouane is with Hassan II University Mohammedia-Casablanca, Department of Physics Avenue Hassan II B.P. 150 Mohammedia Morocco, (rouane.mohammed@gmail.com).

Ahmed Fahli is with the Hassan II University Mohammedia-Casablanca, Department of Physics Avenue Hassan II B.P. 150 Mohammedia Morocco, (fahli@uhp.ac.ma).

Mohammed Moussetad is with Hassan II University Mohammedia-Casablanca, Avenue Hassan II B.P. 150 Mohammedia, Morocco, (m.moussetad@gmail.com).

Abdelatif Khaldouni is with Hassan II University Mohammedia-Casablanca, Settat Department of Physics Avenue Hassan II B.P. 150 Mohammedia, Morocco, (abdelatif.khaldouni@gmail.com).

Ahmed Naddami is with Hassan I university, Department of Physics, B.P. 577, Settat, Morocco (ahmed.naddami@gmail.com).

Submitted 30 April 23014. Published as resubmitted by the authors 13 September 2014. 